\title{
Business Cooperation Networks: Ecosystem Interaction in Small and Medium-sized Companies
}

\author{
D’Oliveira, J. L. P. ${ }^{1 *}$, Guedes, L. G. de R. ${ }^{2}$, Pasqualetto A. ${ }^{1}$ \\ 1 School of Engineering, PUC Goiás, Goiânia, GO, Brazil. \\ 2 School of Electrical and Mechanical Engineering and Computer Science at UFG and School of Exact \\ Sciences and Computer Science at PUC Goiás, Goiânia, GO, Brazil. \\ * Corresponding author. Tel.: + 5562 981452525; email: joseluiz.doliveira@yahoo.com.br \\ Manuscript submitted August 26, 2016; accepted February 12, 2017. \\ doi: 10.17706/ijeeee.2017.7.1.59-69
}

\begin{abstract}
This article discusses the importance of regional business cooperation networks that are formed by micro and small-sized businesses which consist in efficient ways to create work and wealth, in addition to sustainable development and the search for cleaner production. It is understood that cooperation networks are eco-systemically. By having such characteristic they bring together several companies that aim to achieve corporate gains. From the micro and medium-sized businesses point of view their importance noticed by the others members of the network, its flexibility for the ability of quickly making a decision, and the close relationships of trust among its managers are the biggest success factors for the establishment of network cooperation.
\end{abstract}

Key words: Business cooperation, enterprise networks, small and micro-sized businesses.

\section{Introduction}

Cooperation is an agreement that establishes strategic alliances allowing different stakeholders not only to reduce uncertainty and market turmoil, but also to combine advantages with a view that the overall benefit is greater than the act of individual action. It may be temporal when its objectives are achieved, being indefinite or limited [1]. The Micro and small-sized businesses - MSB segment is legally recognized as an integral part of the corporate structure of all countries of our planet.

If on one hand, the MSBs are fragile in many structural aspects, such as: Small scale disadvantages; management and planning issues; shortage of financial resources; access problems to technology, difficulties in communication and marketing; and competition from large corporations. On the other hand, The MSBs possess a range of attractive features showing an influential reality, such features are: it embodies the entrepreneurial potential; it is the biggest job generator; it is flexible, customized and dynamic; it reaches markets with low demand and remote location. A promising solution to MSBs is concentrated at a point of fundamental importance: the junction in a single entity in its business environment. They work together to overcome the inherent weakness of their living conditions. At the same time, they manage to maintain individuality and decision-making autonomy, inside associative and democratic organizations. In this case, a private individual prevails over the legal entity's financial capital. Therefore, Small and Medium Businesses - SMBs are the first companies that meet retail demands needs in less time due to new potential consumption. Even in demographic, regional or local variations, it establishes geo-marketing dynamics and technical logistics in real time, being compatible with the new demands. That is, with promptitude, 
satisfying consumers according to their consumption needs.

In this innovation environment, with interaction between different aspects we can get to the meaning of a keyword: "cooperation". The European Commission defines the term "cooperation" as the relationship between independent partners [2]. So that adds up its efforts and resources in a joint process for valuing creation. Therefore, it is implied that "cooperation" is the integration between partners whose structure promotes partnership. The sum of efforts between the cooperative and several partners may result in building a network. Accordingly, the network has the potential to acquire synergy. We must go further, that is, to act so that there is value creation in the network. This means that the knowledge division and exchange of ideas are of great importance. However, it is essential to encourage trust building between partners.

The network cooperation idea is in the society's contemporary consolidation process. It is widely used as an explanation for organizational phenomena covering interdependent economic agents, the cooperation networks emerge as a paradigmatic brake while conducting business. The global expansion of markets, the extremely fast advances on technology, the greater ease of information exchange and the end of stable competitive advantages, among other factors determined to overcome the traditional competition mode which was set on the hierarchical bureaucracy inherent to large corporate structures.

With the new technologies for Business Management and the organizations that emerged from recent socioeconomic transformations it made possible the birth and growth of smaller enterprises [3]. Thus, this study leads to the acknowledgement that current socioeconomic contingencies can be addressed through joint coordinated actions through corporate networks.

\section{Business Cooperation Network - What Are They? What do They Do?}

Cooperation networks (horizontal networks) are organizations made up of a group of companies. They basically defend and gather around common objectives, formally linked with unlimited term of existence, with a multiple performance purpose. A key detail: each member keeps its legal individuality. In addition, it participates directly in decisions and it divides equally the benefits and gains achieved by the collective efforts [4].

Cooperation networks have their own way of organizing. On account of its unique nature (e.g.: the need to generate collective and consensual solutions), it needs to build management models adapted to its reality, as well as its specificity [5].

What do the horizontal cooperation networks do? They are meant to unite flexibility and agility features. Such features are common with (in, among) small businesses, but it also contributes to increased scale in the market. This idea is based on collective gains from the cooperation network concept. It is known that the requirements are increasingly complex associated with meeting different and several competitive dimensions, summarized on issues such as cost, customer service, flexibility, lead-time and innovation. All of that points to this organizational form that may constitute an effective alternative to the development of companies. Of course, if these aspects are associated with systemic and systematic learning, in short, with the innovation that can be generated in the specific environment of cooperation networks, they are highly significant issues. In the twenty-first century, companies direct themselves swiftly toward the use of cooperation / collaboration in order to obtain collective solutions. The recommended goal is to improve their competitive strategies in the market [5].

It is understood that cooperation networks are ecosystems. By having these features they gather several companies that aim relationships to achieve collective gains, yet this is always accomplished by building on common interests of its entrepreneurs [6].

The importance in the creation of effective development opportunities for networks and companies 
associated with them is striking; add to it the competitive dynamics of the global economy together with the information and communication technologies that increasingly emphasize the importance of relationship in business results. With easy communication established between organizations from any place in the world structures and competitive rules change with greater speed from the moment that companies are provided with more and better information to improve their actions.

This means to confirm that the culture of actions remains intact. It will be crucial to encourage relationships inside and outside the network. Besides, it leverages new information, knowledge and solutions perspectives for new business to flow constantly by the network and its associated companies [5].

SCHERER and ZAWISLAK state that, once established, the network can be regarded as a new coordinator activity. Therefore, it must have at its disposal a set of new knowledge, resources, skills and competences [7].

ORSOLIN and PERUCIA describe the relationship criteria (Table 1) [8].

Table 1. Network`s Relationship Criteria (Internal and External)

\begin{tabular}{|c|c|}
\hline \multirow{6}{*}{ Internal Relationship } & Members' contributions with improvements to the development of the network. \\
\hline & Conducting annual events for social integration among members. \\
\hline & $\begin{array}{l}\text { Conducting annual events for social integration among employees from associated } \\
\text { companies. }\end{array}$ \\
\hline & Do all members have the same level of cooperation in the network? \\
\hline & $\begin{array}{l}\text { Members' engagement in the relationship process with the board, implementing } \\
\text { proposed actions. }\end{array}$ \\
\hline & $\begin{array}{l}\text { The existence of regular meetings between members, outside the council to discuss } \\
\text { and resolve issues related to the network. }\end{array}$ \\
\hline \multirow{5}{*}{ External Relationship } & Projects' development in partnership with other cooperation networks. \\
\hline & A process to identify potential network partners. \\
\hline & Network anticipation about members' needs and expectations. \\
\hline & The network initiative to interact with the government, universities and community. \\
\hline & Develop projects in partnership with other partners (except for suppliers). \\
\hline
\end{tabular}

Source: Orsolin and Perúcia [8].

Balestrin and Verschoore state that: "the formation of networks presupposes relations of three essential conditions: common goals, interaction and management" [4]. Through good management the interaction within the network provides the identification of common goals, which in turn are transformed into results and competitive benefits. This process feeds back the atmosphere of cooperation between the agents involved.

\section{Cooperation between Small and Medium-Sized Businesses}

Innovation is intrinsically linked to the resources needed to achieve itself. Therefore, it can be efficiently made possible with the formation of cooperation networks [4].

In this innovation scenario arising from the interaction between different elements, we realize the importance of the keyword: "cooperation". The European Commission, defines it as the relationship between independent partners that combine their efforts and resources on a joint process of value creation [2].

Therefore, business cooperation is the integration between partners. They share the same structure that promotes partnership. With this being said, cooperation between several partners can lead to the construction of a network. In turn, networking has strong potential to gain synergy. The Exchange of ideas and the knowledge sharing are crucial so that there is value creation in the network. So for all of this, it is 
extremely necessary to build trust between partners [8].

It is known that SMBs often encounter difficulties in the competition world. This results from issues such as high production costs, small-scale, low management information (particularly in relation to market behavior), employees not trained well enough, deficiency in the product field and technology process as well as line of credit available and misuse of practices and available management techniques [5].

Cooperation is faced with some difficulties, this process suffers by barriers such as desire to maintain Independence (39\% firms); lack of information about who to cooperate with (16\%); and lack of interest in disclosing important information to other SMBs cooperation. In this study these barriers were classified into two groups: the first group states the fear of losing independence, not showing interest in sharing information, and the high risk involving it; and a second group called institutional barriers, whose main characteristic is the lack of information about relevant partners, different languages and cultures, legal or prescriptive restrictions [2].

Micro and small businesses cooperates aiming first to win new and larger markets. On the other hand, medium businesses are seeking for cost reduction. Informal cooperation is usually made among micro and small-sized businesses; most medium-sized businesses cooperate more formally than informally. Another revelation is that micro-sized businesses have fewer partners than the small ones, and the small-sized have fewer partners than the medium-sized. The frequency in which these businesses make with their partners was also evaluated. In this regard, micro and small-sized businesses make contacts several times a week, while medium-sized businesses make contacts at least once a month. A common fact: micro, small and medium-sized businesses share the idea that the main barrier to the cooperation process is the desire to maintain its independence [2].

For the permanence and strengthening of micro and small businesses in the regional market, it is evident the search for more associated companies. After all, the greater the number of companies involved, the greater the power bought on the domestic and international markets. Finally, it is clear that Business Cooperation Network currently a major viable alternative to the survival and growth of micro and small businesses in the midst of a highly demanding and competitive market.

\section{Small and Medium-Sized Business Network Structure}

ANDRIANI, JONES, PERKMAN, SENA \& DELBRIDGE state that business cooperation network - BCN and regional cooperation network - RCN have the following characteristics [9]:

1) A large number of companies and institutions specialized in interdependent economic activities;

2) Companies that specialize in different aspects of the value chain; because of their complementarity companies are integrated by external division of work resulting in input-output links;

3) Companies are embedded in a dense network of unusual interdependence (social and cultural) that creates opportunities for mutual learning and raises the level of cooperation;

4) Balanced process of decision making; which does not show clearly its hierarchical characteristics (this means a horizontal governance structure);

5) Institutional thickening, which is the existence of public and private institutions and organizations that are able to support BCNs growth.

Cooperation networks are tools that can stimulate the competitiveness of small and medium-sized businesses in regions and countries through innovation. This view is shared by many, including academics and authorities. However, it is an arduous task, this happens because the current competitive innovation environment occurs through non-sequential interactions between different companies, universities and research institutions. In other words, it is a slightly different way than the traditional way in which research and development centers transform basic research from universities into applied products and processes 
[10].

Collaborative arrangements can be found with various denominations in several federal units. They aim to gain competitive advantage over larger companies. Research and case studies done with participating network companies on federal unit realize that the associated companies are benefited by several factors, which they would not have if they were alone [11].

With the massive communication evolution, especially after World Wide Web in the early 1990s, the most remote locations of the world found themselves very close, and information on technology have become widespread with admirable agility. But even with this remarkable progress, small business owners still face enormous difficulties to enhance their activities and businesses, especially if they act individually.

The following are distinctive considerations on SMBs:

1) SMBs serve as a knowledge transfer vehicle that may become accessible by large companies through transfer or acquisition of Technologies;

2) SMBs increase competition in the markets through new ideas and human capital embedded in the workers' knowledge;

3) SMBs increase diversity in the markets and can develop and generate increased productivity in companies [12].

SMBs cooperation network organization occurs by several factors, and its participants can earn different types of gains. It even allows it to obtain some competitive advantages such as scale gains and market power, providing solutions, learning and innovation, quality and reduced costs and risks. These benefits are achieved by the joint action of a wide range of companies, whose condition of permanent partnerships do not prevent them from maintaining their management autonomy [4].

A cluster of companies without a certain degree of coordination does not constitute a regional BCN. To reach to this condition, the existence of cooperation projects is required. This role can be assumed by creating and maintain institutional thickness, or formal organizations with a high level of interaction. Giving support to companies in several ways is what it is expected of them; or social institutions that promote a dense, informal collaboration between people in companies and organizations. They are important to BCN's growth and success, as they stimulate innovation capacity as a property from the region [2].

More efforts are need to, among other reasons, introduce management structure to BCNs. ANDRIANI, JONES, PERKMAN, SENA \& DELBRIDGE also consider that, among other important issues (that need to be better analyzed) there is a need to understand more deeply which types of infrastructure are necessary and, perhaps more importantly, how to encourage small companies to make good use of such infrastructure [9].

It is important to emphasize the significance not only of external economies, but also of deliberate actions to reach collective efficiency. It can be concluded that such formal and social institutions that have their own network management are fundamental to direct it to the continuous performance improvement and innovation, thus reducing the probability to decline it, due to a rigid and inflexible structure to changes and innovation.

To paraphrase Ketels, we can say that, in order to promote more effective policies for this segment, one should keep in mind some important points [10]:

1) More information about the current status of BCNs should be raised;

2) Different BCNs and different regions' specific characteristics should be considered in BCNs development policies;

3) BCNs should be seen as a part of a broader agenda for competitiveness, i.e.: efforts for BCNs and regions' economic development need to be better integrated;

4) BCNs can be observed as an opportunity to define the rules of the private and public sectors in economic policy. In this case, each one takes responsibility for their specific areas of competence in 
the business environment.

It should be remembered that the information and the knowledge transmission within the cooperation network flows through formal and informal learning processes. Consider also that joint cooperation actions that reduce risks, that increase scale and share resources tend to have a more structured and formalized decision-making process [13].

Clearly, hierarchy's traits will always occur, whether it's in the form of a businessman who takes on operations management or in form of a hired manager that will establish priorities even when he/she is a subordinate.

The network cannot be "built", such as the attempt undertaken with action research. It has no volitional basis, but rather motivational. It is a mistake to structure it from a mere impulse. On the contrary, it is necessary to identify the fundamental interests of its primary agents and the recognition that these interests can be shared. This way it may generate common gains that will be made possible, in particular, through the culture of participation and exchange [13].

The consultants are directly responsible for the formation and consolidation of the network process. They are the ones that initiate contact with entrepreneurs for participation in awareness meetings, to present the program and to motivate cooperation. They act as group of facilitators in common activities and identify possibilities of joint actions for common troubleshooting and for the enhancement of opportunities of the group. They also have the responsibility to tailor the best legal formatting and public registry (statute, bylaws and code of ethics), and to constitute the board and assist in forming work teams.

After the network is created it is necessary to choose its brand with the support from agencies specialized in corporate advertising, then the network's presentation is made to its potential suppliers to show its brand and its potential as a buyer and partner. Once the network is established an event organized by its entrepreneurs and supported by the Program is held to launch it to its appropriate audience. Networks will start to operate with collective tools such as a business center which will allow more favorable gains in terms of: purchase; shared marketing which enables the network to develop advertising campaigns strengthening brands and establishing a common concept; an alliance center to establish partnerships with suppliers, distributors, service providers, consultants, etc. In addition to these, several other collective tools are beneficial to companies within the network.

At the end of the follow-up period, consultants will assist on developing the long-term plan and act as network facilitators, receiving occasional demands and seeking new opportunities for partnerships and alliances.

\section{Competitive Advantages}

Companies operating in the market in individual conditions are in disadvantage with companies operating in business cooperation networks because they have structural and superior organizational powers, and consequently increased market power.

There are significant number of entrepreneurs trying to win heroically market's competition, but what has been seen it is that the best regional companies are being sold to larger groups. And so, people begin to run out of resources, out of profits and dividends in local and regional trade that are taken to other economies, far from benefiting the working class. In this regard, it is recommend to establish new productive and organizational means for entrepreneurs success, and these entrepreneurs need to organize themselves in BCNs to perform an easier benchmarking job in addition to having more negotiating skills and probabilities of victory reaching social goal and profitability, and as a result, its continuation.

The combination of the empiric and academic field is a research opportunity that could contribute to the companies' knowledge that will have a basic theoretical framework to establish them as a BCN directed to 


\section{Cleaner Production [14].}

Studies show that there is a strong correlation between the maturity of adopted management mechanisms and the effectiveness of economic, financial and social networks [15]. Therefore, with a group of small business owners organized in BCN in various cities, it will be possible to envision a new dimension of productive and social life for every citizen inserted in the process, and to increase their social life quality. A new culture of corporate diligence may occur with organized BCNs at a more auspicious life quality level to each citizen-entrepreneur participant and will undoubtedly help to make them more interested institutionally in social organization, and to participate more effectively in the economic progress of their city.

Consequently, BCNs small and medium entrepreneurs will introduce its participating citizens in a logical and technological production system, enabling the business culture absorption, providing participatory life quality in society, in addition to allowing the perpetuation of its professional activities as suppliers to the consumer market.

With the auspicious spirit in the pursuit of internal growth several work processes can be efficient and organized by reworking the network, and a major increase of competitiveness can be expected even though there's the companies' proximities it. To this end, new paradigms must be improved: varieties of products, prompt delivery, agility, technical expertise, superior quality, procedural experience, management flexibilities, and other aspects become naturally desired due to new working and business cultures that can be incorporated to the company's network. Being able to count on the availability and readiness of coaching professionals through the use of effective techniques can improve personal and professional performance of network members in several action plans. Simultaneously, the possibility of expanding the distribution network becomes accomplishable since there is more agility and speed the customer base gets wider, and a bigger and more structured supply chain. The number of stakeholders will increase in proportion to the degree of efficiency and effectiveness of each company in the network.

The social function of every business is the profit, and that is crucial for its survival. Every network manager and each associated company searches incessantly and undoubtedly for the profit's increase and the benefits. As a part of this struggle, there is a fundamental requirement: the "cost reduction". Companies in the network have some advantages in order to launch their products and / or services on the market. In case of joint import of raw material, the first contacts, the shopping, the transport, and even the customs solutions are facilitated by the action of associated companies, being able to count on better advices and more efficient employees. Shared advertising expenditures are at a reduced cost even in large promotional campaigns, so it's possible to achieve greater awareness of its products and the strengthening of its own brands, which are quality identifying. By having Joint Procurement procedures it is possible to implement new products and useful processes, thereby streamlining the desired effectiveness, using the Software Development by establishing appropriate systems for management and production processes. Another important point: they may have the external or internal advisory with more qualified managers, members and associates from PMI, or authorized members. They are able to deploy PMBOK, which has become the basic pillar for project management and the direction of a conscious and proactive manner. The Speed of Prototyping is very important in the aggregation of competitive values, seeking the expertise of new businesses and new products. With companies associated in a network, the Joint Development of molds and tools becomes easier by decreasing individual costs and for the promptness required by all at the same time.

The competitive advantages are similar to competitive attributes listed by VERSCHOORE \& BALESTRIN in [16]. The authors emphasize that the networks the following main competitive factors: economies of scale and market power; providing solutions; learning and innovation, reducing costs and risks, and social 
relations. However, the authors neglect the important factor of Cleaner Production, which also has its contribution in the companies' accounting environmental responsibility marketing.

In cooperation networks, smaller companies may reach the market power of large cooperation, without paying the costs of bureaucracy and inflexibility that characterize them. Cooperation between small businesses and the network rears its ability to competition before the largest players in the market segment in which they compete.

Strengthening the competitiveness of the companies associated to a network is seen as the main strategic factor among its results. Six different competitive gains were listed by [16]: Major Scale and Market Power; Generation of Collective Solutions; Cost Reduction and Risk; Capital Accumulation; Collective knowledge and learning; and Innovation through Cooperation Networks.

The main idea of the Cooperation Networks Program is to bring together companies with a common interest in cooperation networks, making a legally established entity without capital share, which maintains the legal Independence and individuality of each participating company. A company's growth and competitiveness strategy requires a close attention to the cooperation issue and should take into account new relations quality linking business entities, whether it's the business networks or it's just social networks [17].

A network's development allows joint actions to be achieved, facilitating the solution of common problems and enabling new opportunities which would not be possible if the company were by itself.

Integrated companies can reduce and share costs and risks, conquer new markets, qualify products and services and access new Technologies, proving the idea that the whole is greater than the sum of its parts.

These actions have stood out for their potential in strengthening micro and small companies, to ensure better competition to the current competitive market demands.

Micro and small businesses can obtain benefits from its connections with foreign organizations due to its flexibility. However, policies to support export and internationalization cannot be isolated initiatives that end with foreign contacts. Politicians should focus on supporting the exchange of knowledge and experience in maintain contact with foreign entities, as well as creating a favorable framework condition for companies [18].

Some effectiveness indicators of SMBs organized in networks are listed below (Table 2).

Table 2. Effectiveness Indicators of SMBs in Networks

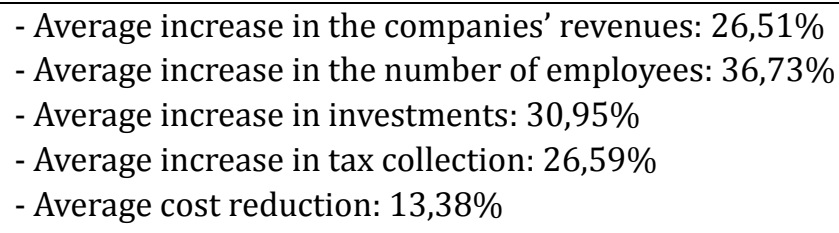

The established networks provide real benefits to the integrated companies. Among them it can be highlighted the arising of the Department of Support for Micro and Small Businesses of the State of Rio Grande do Sul, Brazil:

1) Market's credibility gains, ensuring greater legitimacy in corporate actions and resizing the importance of the company in its business environment;

2) New opportunities for business relationships with universities, government agencies and technological institutions:

3) Valuation of brands, launching differentiated products and shared marketing;

4) Reduction of production costs and investment risks, with joint purchases of goods, supplies, machinery and equipment, and access to major brands; 
5) Standardization of procedures and approvals;

6) Increased productivity and reduction of idleness;

7) Hiring new employees and maintenance jobs;

8) Management training and professional qualification;

9) Advice and consulting in various areas, providing knowledge of new concepts, methods and management styles;

10) Opening and consolidation of markets with national and international marketing structures;

11) Business organization from strategic planning and joint management;

12) Expansion of production scale and offering large orders services' through joint production;

13) Information and experience exchange;

14) Increasing motivation and confidence in the business;

15) Ease access to credit through joint investments actions and recognition of the network structure by the financial agent.

\section{Small and Medium-Sized Businesses and Sustainability}

SEVERO, GUIMARÃES, DORION \& NODARI noticed that in business, Cleaner Production - CP reflects the aspect of environmental sustainability as well as the performance of the organization, showing that the methodologies of CP contribute to the increased capacity and production flexibility, improving aspects of health and worker safety [19]. It is thus obvious organizations' contribution to performance and competitiveness.

Therefore, an eco-friendly environment is provided. Whether it's the human-entrepreneurial relationships, or the search for $\mathrm{CP}$, a confrontation of freedom of expression and decision-making within the purposes for which is aimed at the Business Cooperation Network - BCN is proposed.

Consumers require skills far beyond those that a company can develop in isolation. Predisposition for cooperation network has become essential and its structure became a major characteristic as far as the requirements of $\mathrm{CP}$, with less waste and social, energy, economic and environmental issues targeting sustainability for future generations.

From the human point of view the human being is the most important part of the environment. Human businesses should seek to be considered sustainable: environmentally friendly, economically viable, socially fair and culturally diverse. The idea of sustainability acquires competitive edge contours allowing some markets' expansion. Investing in an ethical and sustainable manner is the basis of the call [20].

Lastly, there is the need for supporting small properties and small business owners, aiming to emphasize that the development of inter-organizational networks is an important factor that can reduce the fragility of these companies and at the same time it build a solid foundation to promote their productive survival committed by the Cleaner Production.

\section{Conclusion}

Regional BCNs should create an important target group of industrial and innovation policies. Thus, it can be an efficient way to create work and wealth in regions. It should work in order to boost sustainable development. In other words, it should contribute not only to economic development but also to social and environmental development. Policies directed at a specific BCN will be more effective if developed at local or regional level. It is understood that BCNs are very different and require individual actions. These policies should be formulated to show the benefits that the companies or entrepreneurs will have engaging in cooperation projects, trying to reduce as much as possible the main barriers to this desired practice.

In its accomplishments as consumption needs suppliers facing retail demand potential BCNs (built by 
companies committed to create people's welfare) convinced with the mission of providing the market with goods and services with promptness and quality, in addition to contribute against economic uncertainty, it provides ideal conditions to increase the best rates of economic growth, therefore, generating more social comfort.

\section{References}

[1] IAPMEI. (2008). Instituto de Apoio às Pequenas e Médias Empresas e ao Investimento / Agência para Competitividade e Inovação. Lisboa, Portuga.

[2] European Commission. (2004). Observatory of European SMEs 2004. Retrieved from the website: http://ec.europa.eu/enterprise/enterprise_policy/analysis/doc/execsum_2004_en.pdf

[3] Castells, M. (2000). The Rise of the Network Society, 4. ed. São Paulo: Paz e Terra.

[4] Balestrin, A., \& Verschoore, J. (2008), Redes de Cooperação Empresarial: Estratégias de Gestão na Nova Economia. Porto Alegre, Brazil: Bookman.

[5] Balestrin, A., Verschoore, J. R., Antunes, J., Orsolin, G., Perucia, A., \& Bortolaso, I. (2010), Práticas de Gestão de Redes de Cooperação Empresarial. Porto Alegre: Editora Unissinos.

[6] Verschoore, J. R. (2006), Redes de Cooperação Interorganizacionais: A Identificação de Atributos e Benefícios para um Modelo de Gestão - Programa de Pós-Graduação em Administração, Universidade Federal do Rio Grande do Sul, Porto Alegre, RS, Brazil.

[7] Scherer, F. O., \& Zawislak, P. A., (2007). Trajetória de crescimento em redes de cooperação. Enanpad, Rio de Janeiro.

[8] Orsolin, G., \& Perúcia, A. (2010). Redes de Cooperação.

[9] D'oliveira, J. L. P, Guedes, L. G. R., Pasqualetto, A., Silva, S., \& Rocha, M. L. (2016). Business cooperation networks: Risks and benefits. International Journal of e-Education, e-Business, e-Management and e-Learning, 6.

[10] Andriani, P., Jones, C., Perkman, M., Sena, V., \& Delbridge, R. (2005). The Prospects and Pitfalls of Clustering for Innovation and Economic Development. London: Advanced Institute of Management Research.

[11] Ketels, C. (2004). European Clusters. Harvard Business School, Boston, MA. USA.

[12] Böhe, D. M., \& Zsilva, K. M. (2004). O dilema de crescimento em redes de cooperação: o Caso Panimel. Redes de cooperação: uma nova organização de pequenas e médias empresas no Rio Grande do Sul Porto Alegre: FEE.

[13] Sebrae. (2006). Unidade de Gestão Estratégica. Gestão Estratégica orientada para resultados: Avaliação e desafios.

[14] TÁLamo, J. R. (2008). Formação e Gestão de Redes de Cooperação Empresarial. Tese (Doutorado em Engenharia de Produção). Escola Politécnica da Universidade de São Paulo. São Paulo.

[15] Chuang, S., \& Yang, C. (2014). Key success factors when implementing a green-manufacturing system. Production Planning \& Control: The Management of Operations, 25(11).

[16] Passador, C. S., Ferreira, V. R. S., \& Passador, J. L. (2006). Produção Acadêmica sobre Redes no Brasil. Simpósio de Gestão e Informação Tecnológica. USP, São Paulo.

[17] Balestrin, A., Verschoore, J. R., \& Reyes, E. (2008). O Campo de Estudo sobre Redes de Cooperação Interorganizacional no Brasil. Encontro de Estudos Organizacionsis, Belo Horizonte. Brazil. Anais do EnEO. Belo Horizonte.

[18] Ratajczak, M. M. (2013). Business networks and cooperation within the supply chain as a determinant of growth and competitiveness. The European Financial Review.

[19] Ratajczak-Mrozek, M., \& Herbeć, M. (2015). To be independent or balance interdependence?: Policy 
implications for micro and small enterprises. IMP Journal, 10(2), 260-275.

[20] Severo, E. A., Guimarães, J. C. F., Dorion, E., \& Nodari, C. H. (2013). Produção Mais Limpa com ênfase na sustentabilidade ambiental e performance organizacional: um estudo empírico no sul do Brasil. Internacional Workshop Advances in Cleaner Production, São Paulo, SP.

[21] (2014). SRI: Socialy responsable investing. The Forum for Sustainable and Responsible Investment.

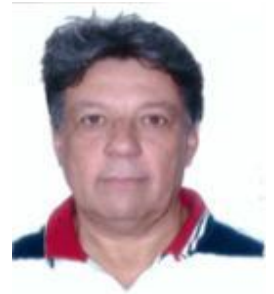

José Luiz Prudente D'Oliveira was born in Goiânia, Brazil and graduated from the Federal University of Goiás, Brazil, with a major in engineering in 1978, holds a master in production engineering from the Pontifical University of Goiás since 2015. He has been a professor in the School of Engineering at the Pontifical University of Goiás (PUC-GO), Brazil since 1979, teaching road constructions. He writes about business and networks cooperation, and sustainability.

He has published an article on business and networks cooperation on the International Journal of e-Education, e-Business, e-Management and e-Learning.

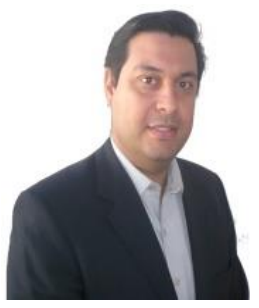

Leonardo Guedes received a BSc in electrical engineering from the Federal University of Goiás, and earned the MSc and PhD degrees from UNICAMP. He was admitted to the Goiás State Board of Engineering in 1993, to the Institute of Electrical and Electronics Engineers in 1994 and to the Project Managment Institute in 2003. He has been President of Goiás State Research Support Foudantion for 5 years and for 2 years the President of Brazilian Association of Electrical Engineers - Goiás' State Section and Professor and researcher at both Federal University of Goiás and Pontifical Catholic University of Goiás. He has also been Director of AROEIRA Foundation at Catholic University of Goiás and also spent two years as a Council Member of the FUNAPE Research Support Foundation at Federal University of Goiás. Prof. Guedes also serves as a Vice-President of the CREA (State Board of Engineering) and as a member of the CNCEEE (National Committee of Electrical Engineering Chambers) as he is currently the Chairman of the Goiás State Electrical Engineering Chamber. Prof. Leonardo Guedes is an Electrical Engineer with more than 10 years' experience in engineering research and development that were gained in major Brazilian research centers. In 1993 he received a Grant from Conselho Nacional de Pequisa - CNPq (National Research Council) for graduate (MSc and $\mathrm{PhD}$ ) research in communications systems at the State University of Campinas UNICAMP (São Paulo). In 1994 an additional Grant from the Development Research Centre of Brazilian Telecommunication Provider (CPqD-Telebrás) and in 1996 ans 1997 he received aRotary International Grants to research, inspect and post-doctoral activities at Ryukoku University and some companies within Japan including Sharp Co., Mitsubishi Co. and Adogawa Electronics Co., among others.

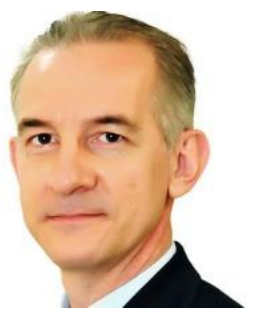

Antonio Pasqualetto holds a degree on agronomy by Federal University of Santa Maria, Brazil (UFSM), and his master and doctorate from Federal University of Viçosa, Brasil (UFV). He is a professor on Pontifical University of Goias (PUC-GO, Brazil) and Goias Federal Institute (IFG, Brazil) in the environment area. He is the coordinator of the development and teaching Stricto Sensu program in industrial and systems engineering at Pontifical University of Goias (PUC-GO) in Goiania, Goias, Brazil. 